Forthcoming in the Journal of Information Technology

\title{
What if There is No Killer Application? An Exploration of a User-Centric Perspective on Broadband
}

\author{
Catherine A. Middleton \\ School of Information Technology Management \\ Ryerson University \\ 350 Victoria Street \\ Toronto, Ontario, Canada \\ cmiddlet@ryerson.ca
}

\section{Acknowledgements:}

An earlier version of this paper was presented at the 2002 Administrative Sciences Association of Canada conference and included in the conference proceedings:

Middleton, C. A. (2002) Learning from the Netcom Trial: Implications for the Deployment of Residential Broadband Networks, in M. E. Hurt (ed.), Proceedings of the Annual Conference of the Administrative Studies Association of Canada, ASAC Information Systems Division, Winnipeg, MB, 70-80.

The author wishes to thank the guest editors and the three anonymous reviewers for their assistance in revising this paper. 


\section{What if There is No Killer Application? An Exploration of a User-Centric Perspective on Broadband}

\section{ABSTRACT}

This paper explores user and provider experiences with broadband networks. Drawing on data from an early broadband trial, and from recent studies of consumer broadband usage, the validity of the commonly held view that widespread adoption of broadband is dependent upon the development of a killer application is challenged. It is argued that access to broadband can be valuable for users without the provision of a killer app, and that the dynamics of broadband development are shifting. As more users become content creators and distributors, and as it becomes easier for consumers to establish broadband networks without help from traditional providers, the existing relationships within the broadband industry will change. Broadband researchers and stakeholders in the development of broadband networks are encouraged to explore and understand the implications of these changes, recognizing that there is much to be learned about deploying broadband in ways that will create the broad societal benefits promised by its promoters.

\section{INTRODUCTION}

This paper investigates consumer usage of broadband ${ }^{1}$ networks. The paper challenges the view that a killer application is necessary for broadband success, by demonstrating that consumers find value in broadband networks as they are currently deployed. Heeding Orlikowski and lacono's (2001) call for a better understanding of the IT artifact, the paper encourages broadband providers to take careful note of how residential broadband has developed to date in North America, and to consider the implications of current documented usage patterns when planning future infrastructure development. Researchers are encouraged to challenge definitions and understandings

\footnotetext{
${ }^{1}$ There is much variation in the way broadband is defined (see Sawyer et al., 2003, for a discussion of this point), but the term is now commonly used, and is generally understood to mean always on, fast internet access, with 'fast' starting at data transfer rates of $200 \mathrm{Kbps}$ (i.e. approximately 4 times faster than dial up modem access). From the perspective of a North American consumer, broadband generally refers to DSL or cable modem service, offering download speeds of 1 - 2 Mbps. Broadband 'light' services are also now available, offering always on service with download speeds of $128-256 \mathrm{Kbps}$.
} 
of broadband, and to develop research agendas that explore broadband developments from multiple perspectives.

Recognizing that broadband adoption rates vary greatly by country (see www.itu.int/osg/spu/statistics and www.oecd.org/sti/telecom for recent data), the paper focuses on consumer adoption of broadband in the North American context. Although Canadian and US uptake rates are different at present, it is suggested that the overall economic and social context in which broadband is being introduced is similar in both countries. The paper does draw on some European data but does not consider the South Korean experience as it has been influenced by a variety of economic and social factors that are not prevalent in North America (Brunel - DTI, 2002; Chang et al., 2003; Lee et al., 2003).

North American consumers have had access to commercial broadband networks for less than 10 years. Although there have been very few studies of what consumers do with broadband access in this period, there appears to be a widespread sentiment in the technology industry that broadband has failed to deliver value to consumers. In particular, the lack of an identifiable 'killer application' (something that will attain 'must have' status, be indispensable and encourage non-users to become users) is considered as a real barrier to broadband development (Carlyle, 2002; Heinzl, 2001; Johnson, 2002; Lessig, 2002; Norris, 2001).

Despite the lack of a killer application, the number of broadband subscribers in North America (and worldwide) continues to increase, with an estimated $25 \%$ of Canadian and $13 \%$ of American households using broadband by mid-2002 (Beardsley et al., 2003). Consumers are creating their own content in many forms (e.g. shared photographs, blogs and web pages), and developing communities of users that share common interests (e.g. hobbies, music file swapping). The use of e-mail and instant messaging 
continues to grow (for narrowband as well as broadband internet users: Jones, 2002; Lenhart et al., 2001; UCLA Center for Communication Policy, 2000; 2001; 2003) and those who subscribe to broadband seem to enjoy using it (Carrière et al., 2000).

It appears then that in the search for a single killer application, the broadband industry has failed (or refused) to recognize that there are already multiple ways in which broadband provides value for consumers. While the value of broadband is recognized by some, this sort of insight is not widely acknowledged in the broadband industry:

When broadband providers abandon their hopes of discovering the Internet's "killer app," they will be closer to understanding its most valuable property. .... Unlike television, the Internet is better suited not to unify the entire nation, but to maintain its diversity. Even AOL ... found that one of its most popular applications was enabling users to divide themselves into countless rooms based on their own interests rather than dishing out "must-see" content for the masses. (Gubbins, 2002)

The fact that the Internet itself is the killer application for these high-level users [the broadband elite] suggests the future of broadband's success may hinge not on what many entrepreneurs have tried to develop: a hugely popular and singular killer app. Rather, it suggests that broadband will likely grow as more and more people gain experience, confidence, and trust online and come to recognize the wealth of material that broadband access can offer a seasoned user. (Horrigan \& Rainie, 2002, p. 16)

This paper considers the implications of rejecting the industry view on the importance of a killer application. Drawing on data from a Canadian broadband trial, supplemented with data from more recent studies of consumer broadband adoption, the paper addresses the question "What if future broadband deployments were guided by users rather than providers?" The paper answers this question by exploring user and provider/industry understandings of various aspects of broadband deployment, including the dominant metaphor for broadband, the role of the provider, the role of the user, control of the network, development of content, network design, bandwidth, key services, and provider strategies. It is suggested that in a broadband environment, consumers will become more active in developing and controlling the content and networks they use. Over time, the roles of existing network and content providers are expected to diminish. 
These findings will be of use to broadband providers, as they seek to understand their ongoing role in broadband deployments. From the research perspective, the paper draws on Orlikowski and lacono's (2001) account of various views of technology in order to investigate future research agendas in the broadband context.

\section{PERCEPTIONS OF BROADBAND SUCCESS: DATA FROM TRIAL AND COMMERCIAL BROADBAND DEPLOYMENTS}

\section{The Netcom Trial}

The Netcom ${ }^{2}$ trial took place in a new subdivision of a suburban Canadian community. A 10 Mbps (megabit per second) broadband network was developed, deployed and operated by a consortium working in a pre-competitive environment. Included in this consortium were hardware, network and content providers; a property developer; educational and government organizations; representatives of the local community; and a range of nonprofit organizations. The trial was to be user-centred, focusing on understanding what consumers would do when provided with broadband access in their homes. Planning for the trial commenced in 1993. The network was operational and serving the first users by late 1996. Although initial plans called for a five year trial, the network was decommissioned at the end of 1998. Users were disappointed by the early ending, but consortium members felt there was little value in continuing the trial into 1999 , especially as commercial broadband services were becoming widely available.

Anyone living in a wired home in the subdivision where the trial took place was eligible to participate, and approximately 70 households did (an uptake rate of about $60 \%$ ). At the peak of the trial, there were close to 200 users ( $70 \%$ adults, $30 \%$ children),

\footnotetext{
2 'Netcom' is a pseudonym. The trial was not affiliated in any way with internet service provider companies operating with the same name.
} 
all of whom accessed the Netcom network through personal computers in their homes. Services offered included high speed internet access, a community mailing list, music and CD-ROM-based content on demand (served over the network), games and healthcare information. There were multiple network access points throughout each house, but the network was designed in such a way that only one user per household could be on the network at any given time.

When planning for the Netcom trial began, there were no well-developed research agendas regarding the provision and use of broadband networks, and no commercial broadband services on which the trial could be modeled. Numerous "information highway" trials were underway (e.g. Brodeur \& Agarwal, 1996; Mason, 1997; Vollmer, 1995; Zeiger, 1995), but many trials were proprietary, and very few results were published. Of those that were published, most focused on technical issues, related primarily to network infrastructure choice and configuration and to mechanisms for deploying content over broadband networks (Bartsch \& Auer, 1997; Di Concetto et al., 1999; Rath et al., 1997; Zahariadis et al., 1997). This technical work was essential for the development of broadband networks, but did not offer any insights as to how consumers actually used the services to which they had access, nor did it offer any guidance to providers as to what services were likely to be successful.

The research conducted at the Netcom trial was among the first to consider these issues. The two main research questions addressed by this researcher at the Netcom trial were interpretive in nature and focused on understanding i) how various stakeholders involved in the trial (e.g. network providers, content providers, community organizations, users) made sense of, or socially constructed, their experiences with the broadband network and services, and ii) how the stakeholders' social constructions of the network influenced the understandings of the network's success (see Middleton, 
2002a, for more detail on this research project). Following Miles and Huberman (1994), a simple conceptual framework was proposed to guide the research. This framework was used to identify informants and issues being studied, without outlining theoretical propositions or hypotheses for testing.

Qualitative data were collected from a variety of sources over a six year period when the author was a participant observer in the trial. (Participation in the trial was limited to providing minimal administrative support for certain trial activities [e.g. minute taking for consortium meetings] and to membership in the trial's research committee once the network was operational). Data were collected through observation of meetings, press conferences, focus groups, training sessions and other events, as well as from trial documentation, press coverage of the trial, focus groups conducted with users in July 1997 and June 1998, field notes from visits to the trial site, archives of the Netcom community listserv, and a series of 34 in-depth interviews with infrastructure providers, content developers, researchers and others involved in establishing and operating the trial (conducted in 1998 and 1999).

When collecting data in focus groups and interviews, stakeholders were not asked to explicitly articulate their social constructions of broadband networks or network success. Instead, data were analyzed to identify instances of sensemaking (Weick, 1995), appropriation (DeSanctis \& Poole, 1994) or construction of meaning (Prasad, 1993).

Given the mix of organizations and individuals involved with the Netcom trial, it was expected that there would be multiple social constructions, or multiple shared descriptions, of the broadband network and services. When the data were analyzed however, it was evident that there were two dominant perspectives on the broadband experience, that of the users, and that of the providers (both content and network/infrastructure providers). While there was of course some diversity of opinion 
and experience within each of these groups, it is the differences between the two groups that are striking. These differences centre around the ways in which the trial offerings were described, and the ways in which the trial outcomes were assessed.

When comparing provider and user understandings of the network and services (the Netcom 'offerings'), two distinct patterns were clear. Providers described the offerings in terms of their components, i.e. network infrastructure, access devices and content. User descriptions focused on what people could do with what they had been provided by Netcom, that is the users described the offerings in terms of benefits and functionality. For example, users talked about using e-mail, listening to music, interacting with CDROMs and playing with the videophones. Most users were not technical experts, and rarely discussed Netcom services in terms of the technology.

The research investigated how various understandings of broadband networks might influence assessments of the trial. Given the differences in provider and user understandings of broadband, were both groups satisfied with their experiences? This question was examined using the IS success framework developed by DeLone and McLean (1992), and modified by Seddon (1997) (see Middleton, 2002a, for more detail on the use of this framework). Figure 1 provides an overview of the dimensions of information systems success, as applied to the Netcom trial.

Figure 1: Information Systems Success Dimensions in the Netcom Context

\begin{tabular}{|l|l|l|}
\hline & Netcom Context for Construct \\
\hline System Quality & $\bullet$ & $\begin{array}{l}\text { ease of use of network and user interface } \\
\text { reliability of infrastructure }\end{array}$ \\
\hline Information Quality & $\bullet$ & accessibility, timeliness, informativeness of community listserv \\
\hline $\begin{array}{l}\text { Perceived } \\
\text { Usefulness }\end{array}$ & $\bullet$ & $\begin{array}{l}\text { extent to which Netcom services (i.e. content and applications) were } \\
\text { useful to the Netcom users }\end{array}$ \\
\hline User Satisfaction & $\bullet$ & extent to which users were satisfied with use of Netcom services \\
\hline Individuals & $\bullet$ & net benefits, for users, of Netcom services \\
\hline Organizations & $\bullet$ & $\begin{array}{l}\text { net benefits, for provider organizations, of provision of Netcom } \\
\text { services }\end{array}$ \\
\hline Society & $\bullet$ & no data collected at this level \\
\hline
\end{tabular}


Users did not think of their broadband experience in terms of separable criteria. They did not explicitly consider system and information quality for example, they simply used the applications that were provided to them, and determined whether they were of value or not. By examining user data however, it is possible to infer an assessment for each of the success dimensions listed in Figure 1.

Data assessing the success of the Netcom broadband network from user and provider perspectives are summarized in Figure 2. Perceived success on a given dimension is indicated with a check mark [ $[$ ]. A cross $[\square]$ indicates that the trial was not considered to be successful on that dimension.

Figure 2: Broadband Network Success, from User and Provider Perspectives

\begin{tabular}{|c|c|c|c|c|c|}
\hline & \multicolumn{2}{|l|}{ User Perspective } & \multicolumn{2}{|l|}{ Provider Perspective } & \multirow{2}{*}{$\begin{array}{l}\text { Comments } \\
\text { Users and } \\
\text { providers in } \\
\text { agreement. }\end{array}$} \\
\hline $\begin{array}{l}\text { System } \\
\text { Quality }\end{array}$ & $\begin{array}{l}\text { Network: high } \\
\text { quality } \\
\text { Interface: some } \\
\text { minor problems, did } \\
\text { not affect access }\end{array}$ & 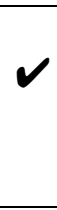 & $\begin{array}{l}\text { Very happy with } \\
\text { network infrastructure, } \\
\text { recognized problems } \\
\text { with interface and } \\
\text { access }\end{array}$ & $\square$ & \\
\hline $\begin{array}{l}\text { Information } \\
\text { Quality }\end{array}$ & $\begin{array}{l}\text { Listserv and e-mail } \\
\text { were extremely } \\
\text { valuable. }\end{array}$ & 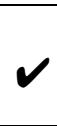 & $\begin{array}{l}\text { Recognized value of e- } \\
\text { mail and listserv. }\end{array}$ & $\square$ & $\begin{array}{l}\text { Users and } \\
\text { providers in } \\
\text { agreement. }\end{array}$ \\
\hline $\begin{array}{l}\text { Perceived } \\
\text { Usefulness }\end{array}$ & $\begin{array}{l}\text { High speed internet } \\
\text { access, e-mail, } \\
\text { listserv were useful. } \\
\text { Other services were } \\
\text { useful for some } \\
\text { users. }\end{array}$ & $\square$ & $\begin{array}{l}\text { Without adequate } \\
\text { content, the value of the } \\
\text { broadband network was } \\
\text { not exploited. More } \\
\text { content would result in } \\
\text { greater perceived } \\
\text { usefulness of Netcom } \\
\text { services. }\end{array}$ & $\square$ & $\begin{array}{l}\text { Users and } \\
\text { providers have } \\
\text { different } \\
\text { perspectives. }\end{array}$ \\
\hline $\begin{array}{l}\text { User } \\
\text { Satisfaction }\end{array}$ & $\begin{array}{l}\text { Generally satisfied } \\
\text { with services, some } \\
\text { small problems. }\end{array}$ & ○ & $\begin{array}{l}\text { Users perceived to be } \\
\text { dissatisfied, yet little } \\
\text { evidence to support this } \\
\text { perception. }\end{array}$ & ( & $\begin{array}{l}\text { Users and } \\
\text { providers have } \\
\text { different } \\
\text { perspectives. }\end{array}$ \\
\hline $\begin{array}{l}\text { Net benefit for } \\
\text { Individuals }\end{array}$ & $\begin{array}{l}\text { Definite benefits } \\
\text { provided for } \\
\text { participation in trial. } \\
\text { No negative } \\
\text { consequences } \\
\text { observed. }\end{array}$ & 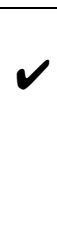 & $\begin{array}{l}\text { Recognized some } \\
\text { benefits for users, } \\
\text { wanted to quantify } \\
\text { extent of benefits. }\end{array}$ & 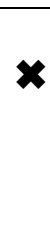 & $\begin{array}{l}\text { Benefits for users } \\
\text { acknowledged, } \\
\text { extent of benefits } \\
\text { differed based on } \\
\text { assessor. }\end{array}$ \\
\hline $\begin{array}{l}\text { Net benefit for } \\
\text { Organizations }\end{array}$ & $\begin{array}{l}\text { No data were } \\
\text { collected to consider } \\
\text { users' perspective } \\
\text { on benefits to } \\
\text { providers. }\end{array}$ & $?$ & $\begin{array}{l}\text { Benefits were } \\
\text { educational, not } \\
\text { financial. Provider } \\
\text { organizations learned a } \\
\text { lot about broadband. }\end{array}$ & ○ & $\begin{array}{l}\text { Definite benefits for } \\
\text { provider } \\
\text { organizations. }\end{array}$ \\
\hline
\end{tabular}


Users considered the broadband network and services to be successful on all five dimensions directly relevant to them, providers did not. The providers' perspective is contradictory to that of the users. Effectively it suggests that providers did not believe that users found value in the services on offer in the trial, despite the fact that users indicated that these services were valuable to them. (This point is explored in more detail in Middleton, 2002b.)

When discussing the outcomes of the Netcom trial, providers repeatedly expressed disappointment that they had not been able to offer Netcom users sufficient content. While the providers did acknowledge that e-mail and the community listserv offered value to users, from the providers' perspective, the popularity of these services was not considered sufficient to make the trial a success. Content was a key component in providers' understanding of broadband, part of the overall package consisting of infrastructure, access devices and content. Content was viewed as something that was developed and provided by parties external to the trial for delivery to users over the network. Content included CD-ROMs, music on demand, and healthcare services. (Interestingly, no user ever described the services made available in the trial as 'content'.) For providers, availability of sufficient content was essential to the success of the trial:

I was trying to figure out if we'd have enough [content] to go. That was our big fear when we first started, and something [the trial manager] was really pushing for was would we have enough when we opened. It was really important that we opened with enough for that first family. And then we managed to do that, we managed to get enough content on.

We tried like crazy to get more content, more CD-ROM titles. We were promised many things, but in the end, even though we were promised things locally ... somehow it just never materialized. Only little drops of it came.

The content sucked, it was a big disappointment, I really wish we could have got some other stuff, especially in entertainment areas because I think the adults would have used the CD-ROM's a lot more than they have. I have to say, I don't think they've done a good job of exploiting what's there, but if there was more content they might spend more time reading through it. 
The providers' assessment was that the trial had been unable to fully develop content and services that were valuable for Netcom residents. As the real estate developer said:

... I don't think we've seen what's really going to happen yet. I think that my passion was tempered and brought more into the real world by understanding that we have to deliver real value to customers to get them to change from having hardwood floor, to investing in something for their family and for the betterment of their lives, I think it is a no brainer, when you have the goods to offer.

Despite the providers' assessment that the lack of content or "goods to offer" meant that there was very little value provided to Netcom users, the users felt that the trial was successful. In particular, high speed internet access, e-mail and the community listserv were highly rated by users:

"I love the community e-mail, incredible responses ... best feature for me."

"E-mail helped to get the community together."

"The e-mail list gives people something to talk about, not just the weather."

High speed is a great asset. We don't have enough time in the day, so it is great to get anything in a matter of seconds. When I get home late I use real audio/video for news. I couldn't get this over a regular speed connection.

The community listserv provided an opportunity for people to use e-mail to communicate with each other. The listserv was the only Netcom service that was continued after the trial ended (with a community member administering a new mailing list). Most users also quickly subscribed to local internet service providers to retain their access to e-mail and the internet, indicating that these services were perceived to be useful. Although individual usage of e-mail was not tracked during the trial, many users indicated that having access to e-mail was invaluable for them.

Internet, e-mail and listserv access were universally popular among the Netcom users. It is less easy to generalize about the perceived usefulness of other services provided to the Netcom residents. User feedback on, and usage patterns for, other services indicate mixed reactions to such services. For instance, there were some users 
who enjoyed the music on demand service very much, while others did not use it at all. Likewise, CD-ROMs were very useful for a small group of users (primarily preschoolaged children), but not widely used by others within the trial. Residents who made use of the healthcare services found them to be useful, but most users did not avail themselves of these services. The videophones were extremely useful for several deaf children within the community, but were treated as a novelty, with little perceived value, by other Netcom residents.

Overall, the Netcom services can be considered successful from a user perspective. Even though not all services were of benefit to everyone, all users found value in at least some of the services offered. Here is a message from a user that was posted to the listserv after the end of the trial was announced:

My family enjoyed being on the trial. We had acess [sic] to free internet, free health nurse and free games for the kids. ...We did not buy our house because it was a smart home, but look at the computer system as a bonus that came with our house. We live in a great community, have the chance to talk to all of you through a community e-mail, and have contributed to a worthwhile study.

Assessments of user satisfaction are heavily influenced by the perceived usefulness of the available applications and services. Although there were certainly some aspects of the broadband experience with which users were dissatisfied (e.g. there was limited choice in CD-ROMs, and additional features were requested for the music on demand service), in general users expressed satisfaction with what was on offer and how it was provided. But given the providers' assessments of the value they could offer to users, it follows that providers generally felt users were dissatisfied with the trial. After all, if value was measured in terms of content offerings, then the limited content on offer meant that limited value was provided to users, leaving them dissatisfied. Likewise, if users were dissatisfied, then providers concluded that benefits to users from participating in the trial 
were small, even though users repeatedly indicated that they received real benefits from their involvement with the Netcom trial.

The data above illustrate provider and user perspectives on broadband service development and delivery. When the users were initially connected to the network, there seemed to be a general sense among all stakeholders in the trial that broadband networks would be valuable because they could deliver content and services to users in their homes. But once residents began to use the Netcom services, they found that not only could they receive the services provided by the consortium, they could also interact with other users. This meant that, contrary to providers' expectations of what their roles would be in the development of broadband networks, users were not reliant upon the providers for all their activities.

It appears that providers did not fully understand how the consumers were deriving benefit from the broadband network. Providers believed that future demand for broadband networks would be driven by content, likely in the form of a yet to be discovered, bandwidth hungry 'killer application', an application they expected to develop and provide. As there was limited broadband content available to Netcom users, providers felt that users should have been disappointed with the trial. But they weren't. Despite the limited availability of content, users found value in other aspects of the trial. As will be discussed below, there is ample evidence in the commercial deployment of broadband networks to show that consumers still find value in basic connectivity that supports file sharing, e-mail and messaging, yet providers continue to believe that without content consumers find little value in broadband. 
Broadband Beyond Netcom: User and Provider Experiences In Commercial Broadband Deployments

The Netcom data were based on the experiences of about 200 , mainly novice, users in the early days of broadband development. It has been suggested that broadband usage patterns might be different now, given that there is a much larger user base, and both users and providers are more experienced with the technology. This section considers recent evidence of broadband usage behaviours. (Note that this remains an under-researched area, and the author is aware of only the few studies discussed below that consider consumer usage of broadband networks and services.)

The most recent data were collected by Dwivedi and Choudrie (2003) in a mid-2002 survey of 104 broadband users in the UK. Year Three of the UCLA Internet Report, "Surveying the Digital Future" (UCLA Center for Communication Policy, 2003), presents data collected by telephone survey from 2000 households in the US between April and June 2002. The Pew Internet and American Life project's "The Broadband Difference" report (Horrigan \& Rainie, 2002) analyzes data collected by telephone in February 2002 from 507 Americans who had previously identified themselves to Pew researchers as broadband users. Anderson et al. (2001) report on interview and transactional data from a 19 household broadband trial in the UK, as well as survey data collected in Europe in 2000 and 2001.

There are many similarities across these data sources. One of the most important findings is that broadband users tend to have been internet users longer than those using dial up. While this does raise the issue of whether certain observed behaviours are prompted by the availability of broadband or simply by the fact that broadband users are more comfortable using the internet in general, it is reasonable to conclude that broadband users are competent internet users who do not have trouble using the 
services available to them. As such, if broadband users are not using certain services, it is unlikely that the reason for this is because they are not skilled enough to do so.

Broadband users are different from narrowband users, but it seems that the differences are primarily related to how they do things with broadband, rather than related to what they do. All the studies cited above indicate that broadband users spend more time online. Broadband's always on feature is recognized as a key benefit, making the internet a quick, easily accessible source of information. Broadband users carry out a wider variety of activities online than those with dial up. In particular, the Pew data identify a "broadband elite", who do twice as many activities in a day as other broadband users. For this group, the internet is an indispensable resource, used for communication (especially via instant messaging [IM] which is used more frequently than e-mail), research, entertainment, transactions and information production. The behaviours of this group of elite users, offering what is arguably the best available indicator of future broadband usage, are consistent in many ways with what was observed at the Netcom trial.

For example, while there is certainly interest in downloading music and video files, the broadband elite data show that on a daily basis, more people are uploading files to share with other users (50\%), than are downloading music (43\%). The elite (especially the youngest amongst them) are active content producers and distributors, creating web pages and displaying their own photos on the internet, as well as sharing other types of files. They do watch video clips and listen to the radio, but on any given day, more among the elite are likely to be bidding in an online auction, looking for medical information, doing research for school or buying travel services than downloading or watching streamed movies (suggesting that the view that broadband creates value primarily by allowing users access to downloadable content shows only limited 
understanding of how broadband is used). Almost half of the elite play games on a daily basis. Although game playing involves use of commercial content (i.e. games developed by content providers), broadband also facilitates the social aspects of gaming, by making it easy for several users to interact and play the same game over the internet at the same time. Overall, broadband allows these users to communicate and interact with others in a variety of ways (chat, IM, gaming), access online information sources, and become content producers, in addition to accessing content from commercial sources.

Broadband users are not waiting for a killer application to make their network access valuable. The Pew study reports that since getting broadband, $32 \%$ of people spend most of their time looking up information, $28 \%$ spend their time e-mailing, and only $8 \%$ spend most of their time downloading files. The UCLA data indicate that people with broadband spend more time communicating with others ( 7.8 hours per week using email and IM) than downloading music and playing games (5 hours per week), and that the relative balance of time spent on communication activities compared to entertainment ones is virtually the same for dial up users as for those with broadband access. More broadband than dial up users in the UCLA study do indicate that the internet is an important entertainment source however. Dwivedi and Choudrie report that $98 \%$ of broadband users in their survey were using e-mail, compared to $34 \%$ who downloaded music, and less than 10\% who downloaded video (while the low percentages of users downloading music and video may be reflective of slow download speeds in the UK, the important of e-mail to these users is undisputed). Anderson et al. also note heavy e-mail usage, and indicate that although broadband users were more likely than those with dial up to listen to the radio or download music, the numbers of users doing these activities were still low as compared to those browsing the internet or sending e-mail. 
Comparing these usage behaviours to those reported in the Netcom trial, it seems that broadband is still being used in ways that are more consistent with users' understandings of broadband success than with the providers' understandings, with much value offered by existing services. Yet the notion that a killer application is required to drive broadband uptake is a very persistent one:

Writing in Fortune, Colvin (2002) observes:

E-mail was the Net's killer app up till now, but as broadband becomes widely available everyone senses that some mind-bending new application will become dominant, and an entire vast industry wonders what it will be.

Copeland and Malik (2002), in an article in Red Herring, quote Mark Hall, vice president of programming for the media streaming company RealNetworks. Hall comments:

Broadband is not the heroin-like addictive form of entertainment that television is, but we are only a couple of years into it. The RealOne service that we are offering depends on addictive applications that have yet to be invented.

Howell's recent academic study of broadband usage in New Zealand (2003) uses somewhat different language to address the issue, but reaches a similar conclusion, suggesting that "near universal low levels of consumer broadband uptake are a consequence of a shortage of applications for which consumers have a cost-justifiable need" (p. 4). Increased demand for broadband would follow through the creation of "applications that use information as inputs and create information as outputs to meet real current and future consumer information production, consumption, and exchange needs" (p. 4). In other words, broadband development is still dependent upon the emergence of a killer application. Broadband will become "a giant engine of commerce that creates businesses that we can't even imagine today" (Desmond, 2003).

In the UK, BT created the Broadband Applications Laboratory to help develop the killer application for broadband. Smith and Leung (2002), employees of this lab, argue 
that "fast Internet access alone is insufficient to drive broadband connectivity" (p. 11), suggesting that:

[U]ltimately, compelling applications will create demand. ...Raw bandwidth, on the whole, does not sell itself - but applications that use that bandwidth do. Compelling applications are essential to drive revenues on new broadband wireless and wireline networks, and thus drive the market for the underlying communications companies and technology vendors. (p. 11)

It is the view of BT that the development of "compelling applications" should be led by providers. This view is shared by those who believe that further development of broadband is essential to spur the recovery of the technology and telecommunications sectors of the economy.

Whether or not broadband holds the only key to prosperity, it is almost certain that without a greater number of people using DSL, cable modem, or wireless broadband connections, many technology companies will be left in limbo. (Copeland \& Malik, 2002)

Broadband will do for the economy what the railroad, electrification, telephone, and interstate highway systems did in their own times. They created new industries, and so will broadband in arenas such as security, education, health care, entertainment -- and others we can't fathom. (Desmond, 2003)

In summary then, it is noted that from the provider perspective, as articulated in the Netcom trial and more recent commentary on broadband, a successful deployment would be one in which providers act as providers, of both network infrastructure and content. The underlying metaphor for this perspective is that of the television, and is a model based on broadcasting. Like TV, broadband is understood as a means of disseminating content from providers to users. Consumers might use their broadband network access to view videos or listen to music, and providers would allow consumers some limited measures of control, for example by making it possible to select specific content for broadcast-type delivery at specific times (e.g. video on demand). In this model of broadband, consumers have no role in creating or shaping the content they receive. 
For consumers, a successful broadband deployment would allow anyone on the network to initiate contact with, generate content for, or distribute content to, anyone else on the network. (The highly successful Netcom listserv is an example of an application that met consumers' needs in all of these areas.) From a consumer perspective, allowing all users to be peers on the network is highly desirable. This vision of broadband success has more in common with the telephone than with broadcast television.

The data presented above show that in the Netcom trial and beyond, providers and consumers demonstrate conflicting visions of success for broadband network deployment. To date these conflicting visions have been resolved with the suggestion that over time a killer app will emerge, and users will become consumers of the broadband content providers will eventually develop. While this is an appealing resolution to the conflict from the providers' perspective, it fails to recognize that in the years since the Netcom trial began, consumers have been finding value in broadband without access to the elusive killer app. As such, it is suggested that rather than investigating the lack of killer apps, the research focus should shift to investigating and understanding the successful aspects of broadband, as defined by those who use it.

\section{BROADBAND WITHOUT A KILLER APP: IMPLICATIONS FOR BROADBAND DEPLOYMENT AND RESEARCH}

In 2001, Orlikowski and lacono published their now widely cited analysis of how information technology artifacts have been studied by information systems researchers. They concluded that "the field of information systems, which is premised on the centrality of information technology in everyday life, has not deeply engaged its core subject matter - the information technology artifact" (Orlikowski \& lacono, 2001, p. 121). It is argued here that in the deployment of broadband, the information technology artifact of interest (a still amorphous, ill-defined combination of network and services), is frequently 
described in a way that reflects only one interpretation of broadband success. As Orlikowski and lacono observe, "[l]t seems that we have left much of our understanding of IT artifacts to the technology vendors and the mass media journalists and pundits who cover them" (p. 133). The danger in accepting a vision of broadband described by vendors and journalists is that it overlooks much of the value that broadband is already providing to consumers.

This section of the paper addresses the question "What if there is no killer application for broadband?". In particular, how might the provision of broadband networks and services change when their development is guided by a user perspective on broadband success, rather than the killer app focused provider perspective presented by vendors and industry observers? And if the deployment of broadband changed, what sorts of research questions could improve our understanding of all aspects of the new environment for broadband development and use?

\section{Implications for Practice}

When broadband success is understood as having two different manifestations, there are a variety of issues broadband providers must understand as they move to extend their services. Figure 3 provides an overview of the key points of difference among the two visions of broadband success. These points of difference are discussed in detail below, and the implications for future deployments of broadband services are outlined. (Note that the purpose of this paper is not to develop testable hypotheses related to future broadband deployments. Rather, the goal is to highlight the differences between provider and user perspectives on broadband, and to outline what these differences imply for future broadband deployments and research.) 
Figure 3: Implementing Broadband Services - Understanding Two Visions of Success

\begin{tabular}{|c|c|c|}
\hline & Provider-Centric View & User-Centric View \\
\hline Dominant Metaphor & $\begin{array}{l}\text { - 'killer app', offered by } \\
\text { providers } \\
\text { - } \text { broadcast television }\end{array}$ & $\begin{array}{ll} & \text { peer to peer (P2P) } \\
\text { - } & \text { community } \\
\text { - } & \text { telephone }\end{array}$ \\
\hline Role of Provider & $\begin{array}{l}\text { - content \& connectivity } \\
\text { provider }\end{array}$ & $\begin{array}{l}\text { - users can provide content } \\
\& \text { connectivity }\end{array}$ \\
\hline Role of User & - consumer of content & - $\quad$ content provider \\
\hline Control & - corporate, centralized & - individual, dispersed \\
\hline Content & - proprietary & - open \\
\hline Network Design & - asymmetrical & - $\quad$ symmetrical \\
\hline Bandwidth & - high & - high \& low \\
\hline Key Services & $\begin{array}{ll}- & \text { video on demand } \\
\text { - } & \text { interactive television }\end{array}$ & $\begin{array}{l}\text { e-mail } \\
\text { - } \quad \text { instant \& text messaging } \\
\text { user friendly content } \\
\text { downloads (e.g. music, } \\
\text { video) }\end{array}$ \\
\hline Provider Strategy & $\begin{array}{l}\text { partnerships between } \\
\text { network and content } \\
\text { providers }\end{array}$ & $\begin{array}{l}\text { abandon alliances between } \\
\text { content and network } \\
\text { providers? }\end{array}$ \\
\hline
\end{tabular}

\section{The Dominant Metaphor: Killer Applications vs. Peer to Peer}

Broadband providers generally believe that broadband uptake will increase once a true killer app is discovered. In their view, providers need the killer app because without it, broadband networks offer little value. Networks are built for distribution of content developed by commercial sources. A killer application would provide this content (e.g. video on demand), and create increased demand for broadband connectivity.

But when broadband is understood through the users' eyes, the perspective on what will drive success changes. Providing simple network connectivity to groups of users with shared interests enables them to develop interactive, networked, interest-based communities (e.g. chat rooms and asynchronous discussion spaces, hobbyists' websites, special interest mailing lists). Network access also allows users to act as peers (equals) on the network, enabling peer to peer (P2P) file sharing. Although some P2P applications, like music and video file sharing, can violate copyright laws, many users 
are developing their own content, on web pages, blogs and through file sharing in perfectly legal ways. Sharing multimedia files works best with high bandwidth, but the Netcom trial also demonstrated the value in low bandwidth, low technology applications that supported basic connectivity among users (e.g. the Netcom community listserv). Such connectivity allows any user to communicate with any other user in a manner that suits both parties, just as the telephone does. Providers who understand their customers well will recognize the value in providing peer to peer connectivity and opportunities to develop online communities, rather than focusing their efforts solely on discovering the elusive provider-developed killer application.

Implication 1: Demand for network services will be driven by peer to peer networking and a desire for basic connectivity, rather than by a single provider-controlled killer app.

Implication 2: Network providers can increase demand for their services by providing users with applications that support the development of peer to peer and community-based networks and services.

The key challenge for providers will be in finding new ways to provide value to consumers, so that revenue generation is maintained. Companies like Friendster (Tesoriero, 2003) and Lavalife (Olijnyk, 2002) are demonstrating that there is a market opportunity to connect people to people.

\section{Roles of the Provider and the User}

The provider view of broadband suggests users receive rather than generate content, yet data indicate that current broadband users are not simply passive content recipients. Users are creating content, including web pages and blogs, as well as personalized collections of music, video and photographs. Some users also distribute content produced by others (e.g. MP3 file sharing). 
The emergence of consumers as content providers and distributors shows their willingness to take control of their broadband experience. At the moment, it is much easier for a consumer to become a content provider than a network provider, but the rapid emergence of wireless networking technologies is already making it possible for individuals to join together and establish their own networks (Marron, 2003). One interesting example of this approach is the Air-Stream project in Adelaide, Australia (www.air-stream.org/?about). It has created a wireless LAN (local area network) for gaming, file transfers and local e-mail that is not connected to the internet, and is therefore not subject to the rules (e.g. download caps) or charges imposed on users by Australian broadband providers. Many game players have taken a similar approach to becoming their own network providers through what are known as LAN parties (Warner, 2000). At a LAN party, everyone brings a computer and all the computers are connected to a LAN, not to a network provided by a commercial network service provider. Although many consumers will not be interested in becoming network providers, they may avail themselves of network services made available by their peers. There are many community wireless networking projects being developed around the world that own and operate network infrastructure and provide connectivity in local communities (see www.freenetworks.org/special/fnorg_faq on this point).

Users place a high value on network access, and are often willing to pay more for connectivity than content (Odlyzko, 2001). When there are many choices for provision of network services, existing providers must find ways to retain their customers in the face of competition. It is suggested that a focus on providing high quality, reliable network service at a reasonable price will be a means of competing with the new market entrants. Without quality offerings from existing broadband providers, their dual role as content and network providers is at risk of being usurped by consumers. 
Implication 3: Content and infrastructure providers can be replaced by users. Existing providers will need to develop new services and clear value propositions in order to maintain a role in future broadband deployments.

\section{$\underline{\text { Control and Content }}$}

In a user-centric environment it becomes very difficult for a network or content provider to control access to content. In contrast to this new world of individual, distributed control, providers are accustomed to a model where proprietary content is tightly controlled by centralized corporate entities (as was the case in the music industry prior to the advent of P2P file sharing). Despite music industry efforts to stop copyright violations and illegal file sharing (e.g. repeated legal actions taken by the Recording Industry Association of America [RIAA]) it appears that providers' ability to maintain tight control over content (and copyright) will continue to erode, particularly as users indicate they are not concerned about the copyright status of downloaded files (Madden \& Lenhart, 2003). Even when users don't create content themselves, they are finding ways to control how content is distributed. This power shift, from corporate control to individual control is also occurring elsewhere in the technology industry, with open source software like Linux a prime example.

Implication 4: Control of content will continue to shift from providers to users. It will become increasingly difficult for providers to maintain control over content distribution.

\section{Network Design and Bandwidth}

Current consumer broadband infrastructure is typically asymmetrical in design, (i.e. bandwidth from the provider to the user is much higher than the bandwidth from the user 'back' to the provider). This design made sense when broadband communication was modeled on broadcasting, because there was no perceived need for high bandwidth 
from the user back to the content broadcaster. But when users become content developers and take more control over content exchange, they want to be able to send content to the network with the same ease, and at the same speed, as they have been receiving it. Users who swap music and video files, or even exchange vacation photos, would benefit greatly from access to symmetrical networks.

Some providers have started differentiating their network offerings (see Canada's Sympatico offerings at sympatico.ca, for example). Rather than providing one type of broadband network access for all users, various market niches have been identified. One such niche product is a high bandwidth service that commands a premium price. From a consumer perspective, the ideal high bandwidth service would be symmetrical, but most current offerings remain asymmetrical in nature. In addition, there is also a market for a lower bandwidth service, offered at lower cost, that provides users with always on connectivity for basic services like e-mail and occasional web browsing. A symmetrical connection is less important in this context, as e-mail and web browsing do not require much upstream bandwidth. However, given a choice, a symmetrical infrastructure is preferred to an asymmetrical one because activities that involve data transfer from one user to another can be done more quickly with higher bandwidth. It is also noted that not every low bandwidth user will be interested in moving to higher bandwidth connections, because for some users, access to basic connectivity is more important than bandwidth (e.g. daily activities revolve around e-mail and information searching, not downloading large files).

Implication 5: Users of high speed networks who are active content producers will demand that such networks offer symmetrical bandwidth.

Implication 6: Not all users will demand high bandwidth connectivity. Demand will exist for always on, low bandwidth networks. 


\section{Key Services}

When broadband services are developed according to a broadcasting model, the services that are expected to be popular are entertainment services like video on demand or interactive television. Video on demand has been promised to consumers for many years now (Dholakia, 1996), and there is some interest in it. In Korea, a service that time shifts television programs is described as video on demand, and is very popular (Brunel - DTI, 2002). But in North America, it is still not clear whether video on demand can be offered at a price that is appealing to consumers and still economically viable for providers. In time, it is expected that this service will become available, although it is possible that this sort of service might be made available using existing cable television networks and personal video recording devices rather than via broadband networks.

The application that is still used most widely by narrowband and broadband subscribers alike is e-mail. This is consistent with a model of broadband usage that enables connectivity among users, and as such, its popularity is expected to continue. Low bandwidth text messaging is likely to continue to grow as well (as is already observed among the broadband elite), both over the internet (instant messaging) and for wireless devices (SMS - short message service).

The other key application in a user-centric environment is peer to peer file sharing, for music, video and other multimedia files. The key challenge here for existing content providers is how to compete with the free (albeit illegal) files that are so easily available on the internet. Although only in the very early days of operation, Apple's iTunes (www.apple.com/itunes/) service appears to have found a way to get consumers to pay for content (Blackwell, 2003). The appeal of iTunes is likely twofold: i) it offers cheap (99ф US per song) high quality music that is available on demand, and ii) it allows users 
to buy music in any way they choose (e.g. single tracks, not just complete albums), moving control of content distribution from the provider to the consumer.

Implication 7: Demand for and usage of high and low bandwidth peer to peer services will continue to grow.

Implication 8: High quality content that can be acquired in ways that allow maximum user convenience and choice may be able to compete with free downloads.

\section{Provider Strategy}

In a broadcast-based model of broadband, consumers purchase a suite of services that includes network access and broadband content. Infrastructure providers have not typically had experience in developing broadband content, thus they align with content providers, who could not get their content to consumers without network access. This is the organizing logic that guided the Netcom trial, and motivated the AOL Time Warner merger.

When the model for broadband success becomes more user-centric, provider strategies need to be reassessed. Does it make sense for network providers to align with content providers, if users are more interested in content they generate than content that is offered by providers? What should content providers do to maintain their access to consumers? These important issues are ones that will be faced by content and infrastructure providers as users continue to exert control over their broadband environment.

Implication 9: Alliances between content providers and network providers will become less common.

Overall, the user-centric view of broadband development presented above suggests that there will be some fundamental changes in the broadband environment. As users become content producers and ignore file sharing restrictions it is becoming more 
challenging for existing providers to control content distribution. Over time, as it becomes easier for users to provision networks, it will be difficult to apply existing regulatory frameworks to non-commercial network providers. Organizations and governments trying to promote broadband uptake (an objective of many Western governments at present) will need to develop relationships with new players in the broadband environment, as the market becomes more competitive and control shifts away from small numbers of commercial content and network providers to larger numbers of userled providers. As more consumers become actively involved in shaping and creating their broadband environments, and in demonstrating the value of broadband, there may be less need for direct government intervention to promote broadband usage. As broadband becomes part of users' daily lives, users will lead the agenda to develop ehealth, e-learning and e-government applications, applications that governments believe are essential to achieving productivity gains from broadband.

\section{Implications for Research}

The discussion above outlines the implications of challenging a widely held belief about the development of broadband networks and services. Consistent with Orlikowski and lacono's (2001) argument that information technology artifacts are under theorized, it is suggested that current understandings of broadband are limited in scope, and that assumptions about usage patterns and determinants of demand are not the only ones that are subject to challenge. In this final section, three views of technology identified by Orlikowski and lacono (tool, proxy and ensemble) are briefly considered as a means of identifying relevant research questions about the future of broadband developments. No single view of technology can adequately describe the complex nature of broadband technologies as they are adopted by various stakeholders, for various purposes, in multiple contexts, and at different times, but a consideration of multiple views can help 
the articulation of theoretically sound conceptualizations of broadband. Suggestions for theorizing about broadband are provided, based on the premises outlined by Orlikowski and lacono.

\section{Broadband as a Tool}

The tool view of technology suggests that there is a well-defined understanding among a technology's users of what that technology is for and how it is used. This paper described user and provider perspectives on what broadband is for, but these perspectives alone do not offer a complete picture of the technology. Although the data presented in this paper did not indicate that broadband users currently view broadband primarily as a productivity tool, technologies are frequently defined in this way, and the promise of increased productivity is frequently used as a justification for encouraging widespread broadband adoption (Ferguson, 2002). Accepting that broadband will be viewed as a tool, it is essential for researchers to consider who is using the tool, and for what purpose. For example, is broadband being used for entertainment? Is it being used to foster community and to share content and applications among people with similar interests? Is it being used as a conduit to access healthcare, educational or government services (a scenario frequently presented by those who see broadband as a productivity enhancing innovation)? Each of these uses would require somewhat different approaches to deployment. It is also noted that views of what broadband can do, and what sort of tool it is, will be dynamic, changing over time as new uses emerge. For this reason, it is essential to continue to revisit questions about the nature of broadband, taking a similar approach to that initially used in the Netcom trial. 


\section{The Proxy View: Broadband Diffusion}

The proxy view of technology focuses analysis of a technology on a specific characteristic or value, considered as a proxy for the "essential aspect" of that technology. Much research in this tradition focuses on technology diffusion, which is a popular theme in broadband research at present (see www.itu.int/osg/spu/ casestudies/\#broadband and Chang et al., 2003; Howell, 2003). But one of the difficulties in applying general lessons and insights from country-specific case studies is that many of the aspects that define broadband are not the same. As Orlikowski and lacono observe, "IT artifacts are always embedded in some time, place, discourse and community" (p. 131). Governments and providers may act in different ways, there are different regulatory environments and pricing schemes, and national cultures influence certain aspects of broadband usage and deployment, meaning that some applications will be more widely used in some countries than in others. While these comments seem obvious, without acknowledging that broadband must be recognized and investigated as a complex and contextual IT artifact, it is simple (but potentially erroneous) to make broad generalizations about broadband in various different contexts. Researchers must carefully document the context in which broadband research takes place, and consider the extent to which conclusions are impacted by the research environment.

\section{The Broadband Ensemble}

This view looks at the interactions between people and technologies, suggesting that analysis that considers just social, or just technical, aspects of a technology is incomplete. Taking a production network approach means focusing on the supply of a technology (Orlikowski \& lacono, 2001, p. 126) and would encourage an investigation of broadband at an "industry and nation-state" level. This perspective could produce much 
different insights than those generated by considering users and providers, through investigation of, for example, the relationships between regulators and technology vendors, or of the importance of government objectives in developing broadband. As was noted earlier, governments view broadband as a productivity engine, and the technology industry views broadband as a potential cure to its current financial woes. Examining broadband deployment from these perspectives would generate new insights. For instance, it is possible to explore how broadband is developed for political purposes and how certain aspects of development reflect certain business decisions.

As broadband diffuses more widely, there will be many opportunities to investigate the complex ensemble of people and technology embedded in specific social contexts. Case studies of this sort will generate insights on how broadband becomes defined in certain contexts, and will enable informed discussions of why deployments of broadband differ.

Broadband research is in its infancy. As has been suggested in this paper, many aspects of broadband deployment will change over time, as consumers become more familiar with broadband, and as the broadband industry determines its long term role in the process. From a research perspective, it is important to continually explore and test the assumptions that are underpinning broadband deployment. As this paper shows, challenging widely held beliefs about the nature of broadband diffusion can result in new understandings of how broadband might develop. Orlikowski and lacono's views of technology can be used to develop research questions in the broadband environment, offering value by providing different ways of investigating the broadband artifact. Over time, more theoretically driven approaches will be adopted, but at present there is much to be learned from research that focuses on documenting and describing the emergence of broadband networks, applications and the stakeholders that interact with them. 


\section{CONCLUSION}

Patterns of technology diffusion and adoption are rarely predictable (Rogers, 1995), yet certain themes do recur. When the telephone was first invented, it was viewed as a broadcast device. People gathered around the telephone to listen to concerts, and what was referred to as 'idle chat' was strongly discouraged. But over time, usage of the telephone changed. People discovered value in connecting with each other, and the telephone's initial use for broadcasting disappeared. (See de Sola Pool, 1977; Fischer, 1992; Rowland, 1999, for discussions of the evolution of the telephone.) Today it is not clear whether broadband diffusion will be spurred on by the advent of a killer application, in the broadcast tradition, or whether broadband deployment will come to more closely resemble the peer to peer nature of the telephone.

This paper puts forth a strong argument to suggest that over time, broadband usage will more closely mirror telephone usage than broadcasting. The current evidence suggests that the balance of power is now shifting away from content and infrastructure/network providers, toward consumers, who are taking more responsibility for shaping the broadband environment to meet their own needs (by becoming content and network providers, for example). Specific implications of this shift are outlined in the paper, and should be of interest to providers.

Relationships among broadband stakeholders are likely to be in a state of flux for some time, as they collectively puzzle out visions (not necessarily shared) of what broadband can do, how it can be developed, and who should be involved in the development processes. The paper makes the case that researchers should heed Orlikowski and lacono's (2001) advice to investigate the IT artifact, in order to better understand this sensemaking about broadband, and to investigate its implications. 
Over the next few years, governments will invest enormous sums of money to encourage broadband diffusion. This paper is intended to provoke thought about what form(s) this diffusion might take, and to encourage consideration of a range of possible scenarios. As researchers continue to work in this area, and as diffusion continues, discussion can move beyond the issues of network provision and usage outlined here, with the ultimate objective being broadband deployments that offer benefits that are tangible and real for all stakeholders. 


\section{REFERENCES}

Note that when page numbers are not provided in the reference list or in quotations in the body of the paper this is because the cited material was viewed online in a non-paginated format.

Anderson, B., Gale, C., Jones, M. L. R., and McWilliam, A. (2001) Domesticating Broadband - What Consumers Really Do with Flat-Rate, Always-on and Fast Internet Access, BT Technology Journal, 20 (1), 103-114.

Bartsch, F.-R., and Auer, E. (1997) Lessons Learned from Multimedia Field Trials in Germany, IEEE Communications Magazine, 35 (10), 40-45.

Beardsley, S., Doman, A., and Edin, P. (2003) Making Sense of Broadband. The McKinsey Quarterly.

Blackwell, R. (2003, 12 July) Music Industry Struggling to Tune in on-Line Profits. Globe and Mail, Toronto, B1.

Brodeur, R., and Agarwal, K. (1996, December) Bell Canada Trials Provide High Bandwidth for Interactive, Multimedia, and Internet Services. Telesis, 41-42.

Brunel - DTI. (2002) Investigating Broadband Technology Deployment in South Korea: International Technology Services Mission to South Korea.

Carlyle, P. (2002, 28 March) Content Is King in Battle to Find Killer Application. The Scotsman, Edinburgh, 5.

Carrière, R., Rose, J., Sirois, L., Turcotte, N., and Zabbal, C. (2000) Broadband Changes Everything, www.mckinsey.de/ downloads/knowmatters/telecommunications/broadband chang es.pdf, accessed 27 June, 2003.

Chang, S., Lee, H., and Middleton, C. (2003) The Deployment of Broadband Internet in Australia: Areas for Attention and Implications from Canada and Korea, Proceedings of the International Telecommunications Society Asia-Australasian Regional Conference, Perth, Australia.

Colvin, G. (2002) The 75-Year-Old Killer App. Fortune, 146, 76.

Copeland, M. V., and Malik, O. (2002, 13 February) Jilted by Broadband. Red Herring.

de Sola Pool, I. (1977) The Social Impact of the Telephone, MIT Press, Cambridge, MA.

DeLone, W. H., and McLean, E. R. (1992) Information Systems Success: The Quest for the Dependent Variable, Information Systems Research, 3 (1), 60-95.

DeSanctis, G., and Poole, M. S. (1994) Capturing the Complexity in Advanced Technology Use: Adaptive Structuration Theory, Organization Science, 5 (2), 121147.

Desmond, N. (2003, February) Let's Underwrite Broadband. Business 2.0.

Dholakia, R. R. (1996) Taking Movies-on-Demand to Market, in R. R. Dholakia, N. Mundorf, and N. Dholakia (eds.), New Infotainment Technologies in the Home: Demand-Side Perspectives, Lawrence Erlbaum Associates, Mahwah, NJ, 75-88.

Di Concetto, M., Pavarani, G., Rosa, C., and Rossi, F. (1999) AMUSE: Advanced Broadband Services Trials for Residential Users, IEEE Network, 13 (2), 37-45.

Dwivedi, Y. K., and Choudrie, J. (2003) Investigating the Impact of Broadband Upon the Users on-Line Habits and the Usage of Internet Services, Proceedings of the International Telecommunications Society Asia-Australasian Regional Conference, Perth, Australia.

Ferguson, C. H. (2002) The US Broadband Problem (Policy Brief 105): Brookings Institution, Washington, DC. 
Fischer, C. S. (1992) America Calling: A Social History of the Telephone to 1940, University of California Press, Berkeley.

Gubbins, E. (2002) Killer Apathy. Telephony, 242, 16.

Heinzl, M. (2001, 14 June) Broadband Carriers Are Hunting for 'Killer Apps'. Wall Street Journal, New York, B10.

Horrigan, J. B., and Rainie, L. (2002) The Broadband Difference: How Online Americans' Behavior Changes with High-Speed Internet Connections at Home: Pew Internet \& American Life Project, Washington, DC.

Howell, B. (2003) A New Zealand Response to The United States 'Broadband Problem', Proceedings of the International Telecommunications Society Asia-Australasian Regional Conference, Perth, Australia.

Johnson, M. (2002, 29 July) Killer App Revealed. Computerworld, 36, 20.

Jones, S. (2002) The Internet Goes to College: Pew Internet \& American Life Project, Washington, DC.

Lee, H., O'Keefe, R. M., and Yun, K. (2003) The Growth of Broadband and Electronic Commerce in South Korea: Contributing Factors, The Information Society (19), 8193.

Lenhart, A., Rainie, L., and Lewis, O. (2001) Teenage Life Online: The Rise of the Instant-Message Generation and the Internet's Impact on Friendships and Family Relationships: Pew Internet \& American Life Project, Washington, DC.

Lessig, L. (2002, 8 January) Who's Holding Back Broadband? Washington Post, Washington, DC, A17.

Madden, M., and Lenhart, A. (2003) Music Downloading, File-Sharing and Copyright: Project Data Memo: Pew Internet and American Life Project, Washington, DC.

Marron, K. (2003, 25 March) Wifi Hot Spots Start to Sizzle. Globe and Mail, Toronto, E1.

Mason, C. (1997, 15 November) High Hopes Drowned in Dollars. America's Network, 16.

Middleton, C. A. (2002a) Content and Connectivity: Competing Perspectives on Success in a Residential Broadband Network Trial, Unpublished Doctoral Dissertation, York University, Toronto, www.ryerson.ca/ cmiddlet/thesis.html.

Middleton, C. A. (2002b) Who Needs a 'Killer App'? Two Perspectives on Content in Residential Broadband Networks, Journal of Research and Practice in Information Technology, 34 (2), 67-81.

Miles, M., and Huberman, A. M. (1994) Qualitative Data Analysis: An Expanded Sourcebook, Sage, Thousand Oaks, CA.

Norris, A. (2001, 25 October) Content Caught Off-Side. The Guardian, online edition.

Odlyzko, A. (2001) Content Is Not King, First Monday, 6 (2).

Olijnyk, Z. (2002, 18 February) Matchmaker, Matchmaker, Make Me a Bundle. Canadian Business, 75, 54-59.

Orlikowski, W. J., and lacono, C. S. (2001) Research Commentary: Desperately Seeking the 'IT' in IT Research - a Call to Theorizing the IT Artifact, Information Systems Research, 12 (2), 121-134.

Prasad, P. (1993) Symbolic Processes in the Implementation of Technological Change: A Symbolic Interactionist Study of Work Computerization, Academy of Management Journal, 36 (6), 1400-1429.

Rath, K., Wanigasekara-Mohotti, D., Wendorf, R. G., and Verma, D. C. (1997) Interactive Digital Video Networks: Lessons from a Commercial Deployment, IEEE Communications Magazine, 35 (6), 70-74.

Rogers, E. M. (1995) Diffusion of Innovations, (4th ed.), The Free Press, New York.

Rowland, W. (1999) Spirit of the Web: The Age of Information from Telegraph to 
Internet, (Rev. ed.), Patrick Crean Editions, Toronto.

Sawyer, S., Allen, J. P., and Lee, H. (2003) Broadband and Mobile Opportunities: A Socio-Technical Perspective, Journal of Information Technology, 18, 121-136.

Seddon, P. B. (1997) A Respecification and Extension of the DeLone and McLean Model of IS Success, Information Systems Research, 8 (3), 240-253.

Smith, M. W., and Leung, H.-T. (2002) Finding the Killer Application - The Role of the Broadband Applications Laboratory, BT Technology Journal, 20 (1), 11-21.

Tesoriero, H. W. (2003, 2 June) A Friendlier Way to Date Online. Time, 161, 84.

UCLA Center for Communication Policy. (2000) The UCLA Internet Report - "Surveying the Digital Future": UC Regents, Los Angeles.

UCLA Center for Communication Policy. (2001) The UCLA Internet Report 2001 "Surveying the Digital Future": UC Regents, Los Angeles.

UCLA Center for Communication Policy. (2003) The UCLA Internet Report: Surveying the Digital Future Year 3: UC Regents, Los Angeles.

Vollmer, A. (1995) France Telecom Rolls out Information Highway Trial, Electronics, 68 (6), 8.

Warner, M. (2000, 14 August) Instant Party, Just Add Ethernet Cables. Fortune, 142, 4243.

Weick, K. E. (1995) Sensemaking in Organizations, Sage, Thousand Oaks, CA.

Zahariadis, T., Rosa, C., Pellegrinato, M., Lund, A. B., and Stassinopoulos, G. (1997) Interactive Multimedia Services to Residential Users, IEEE Communications Magazine, 35 (6), 61-68.

Zeiger, D. (1995, 21 February) 22 Firms Join U S West Trial. Denver Post, Denver, C1. 